DOI: https://doi.org/10.24867/13CG13Blagojevic

\title{
PROCENA STANJA I OBNOVA FASADE ZGRADE SOKOLSKOG DOMA U NOVOM SADU SA ASPEKTA TRAJNOSTI I ENERGETSKE EFIKASNOSTI
}

\section{ASSESSMENT AND RENOVATION OF THE FACADE OF THE BUILDING "SOKOLSKI DOM" FROM THE ASPECT OF DURABILITY AND ENERGY EFFICIENCY}

\author{
Anja Blagojević, Fakultet tehničkih nauka, Novi Sad
}

\begin{abstract}
Oblast - GRAĐEVINARSTVO
Kratak sadržaj - Rad se sastoji iz teorijskoistraživačkog i praktičnog dela. U teorijsko-istraživačkom delu govori se o istoriji nastanka Sokolskog društva, kao i ukratko o Pozorištu mladih, te izgradnji Sokolskog doma. Procena stanja Sokolskog doma je urađena u okviru praktičnog dela, koji obuhvata i proračun energetske efikasnosti predmetnog objekta. Pomenuti proračun ponovljen je nakon primene predloženih mera energettske sanacije. Energetski razred " $G$ " pre sanacije je poboljšan u razred " $D$ ” nakon sanacije.
\end{abstract}

Ključne reči: Istorijat, Procena stanja, Energetska efikasnost, Sanacija

\begin{abstract}
The paper consists of theoretical-research and practical work. The theoretical-research part deals with the history of the "Skolski" Society, as well as of the Youth Theater. The construction of building of "Skolski dom" building was also described. The assessment of the condition of "Sokolski dom" building was done within the practical part, which also includes the energy efficiency calculation for the present condition of the building. The mentioned calculation was repeated after the application of the proposed renovation measures. The energy class "G" is improved in "D" thanks to renovation measures.
\end{abstract}

Keywords: History, Condition Assessment, Energy Efficiency, Renovation

\section{ISTORIJAT SOKOLSKOG DOMA}

\subsection{Istorija nastanka Sokolskog društva}

Sokolstvo nastaje 1862. godine u Češkoj koja se tada nalazila u okvirima Habzburške monarhije. Kako slovenski narod nije imao pravo organizovanja vojnih formacija, javlja se želja za nacionalnim ujedinjenjem i oslobođenjem od germanizacije. Tako nastaje sokolstvo kao narodno-vaspitna organizacija sa ciljem telesnog i moralnog vaspitanja čitavog naroda.

Glavni tvorac ideje bio je dr Miroslav Tirš, po kome je i sokolski telovežbeni sistem dobio ime „Tiršov sistem“.

U Novom Sadu 1905. godine osnovan je „Srpski soko“. Vlasti ne odobravaju takav naziv, te su preimenovani $u$ „Sokolsko društvo“.

\section{NAPOMENA:}

Ovaj rad proistekao je iz master rada čiji mentor je bila prof. dr Mirjana Malešev, red. prof.
Već sledeće godine članovi društva počinju sa redovnim vežbanjem na različitim mestima u gradu.

Početkom Prvog svjetskog rata 1914. godine mađarske vlasti zabranjuju aktivnosti društva. Sokoli obnavljaju svoj rad 1919. godine.

Stvaranjem Kraljevine SHS dolazi i do ujedinjenja svih sokolskih saveza, te 1920. godine menja se ime u Jugoslovenski sokolski savez.

Sokoli konačno dobijaju svoj dom 1936. godine.

Izbijanjem Drugog svetskog rada 1941. godine sve aktivnosti Sokolskog društva su prekinute. Po završetku rata rad društva pod nazivom ,Soko“ nije dozvoljen, zbog čega dobija novi naziv "Prvo gimnastičarsko društvo“ Novi Sad, a Sokolski dom je preimenovan u Dom Kulture. Društvo funkcioniše u okviru Fiskulturnog saveza Vojvodine. Gimnastičarski savez se osamostaljuje 1948. godine. Gimnastičarski savez Jugoslavije 1951. godine se naziva Savez za telesno vaspitanje „Partizan“ Jugoslavija.

Sokolski dom dat je na korišćenje 1951. godine Prvom Gimnastičarskom društvu Novi Sad, koje dobija naziv Društvo za telesno vaspitanje „Partizan I“ 1952. godine.

Gimnastičarska sekcija „Partizana“ izdvaja se u Gimnastičarski klub „Vojvodina“ 1980. godine. Gimnastičarski klub „Vojvodina“ vraća svoj prvobitni naziv u Sokolsko društvo „Vojvodina“ 1992. godine.

DFVR „Partizan I“ je pripojen Sokolskom društvu „Vojvodina“ 2002. godine.

Sokolski dom, je proglašen za spomenik kulture Republike Srbije 2002. godine.

Originalni natpis „Kralju ujedinitelju“ ponovo je vraćen 2007. godine .

Po isticanju prava na korištenje Sokolskog doma 2010. godine sokoli postaju zakupci levog krila objekta. Konačno, proglašeni su za vlasnike 2017. godine [5], [6].

\subsection{Izgradnja Sokolskog doma}

Po završetku Prvog svetskog rata sa razvojem Sokolskog društva javlja se potreba za sopstvenim Domom.

Sokolsko društvo podnelo je zahtev za dodelu zemljišta za gradnju 1931. godine. Dobijeno je zemljište površine $6340 \mathrm{~m}^{2}$.

Prikupljanje sredstava, te izrada projekta se dešava tokom 1932. i 1933. godine. 
Projekat, predračun i građenje Doma odobren je 1934. godine od strane Saveza Sokola Kraljevine Jugoslavije (slika 1).

Kraj građenja dešava se 1936. godine, a dozvolu za korišćenje dobijaju 1937. godine.

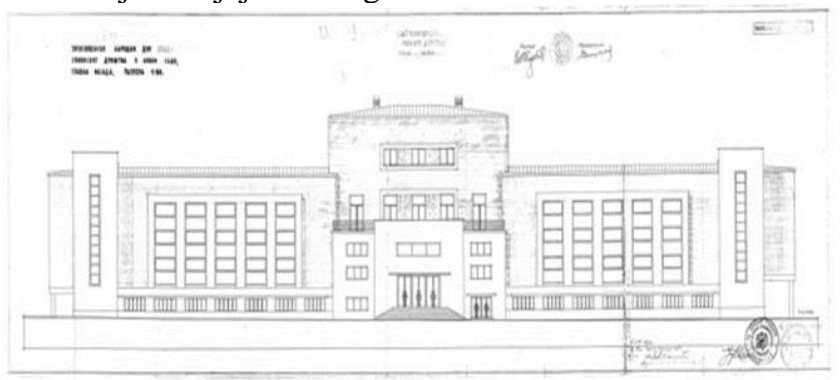

Slika 1. Nacrt zgrade Sokolskog spomen doma arhitekte Đorđa Tabakovića 1934. godine

\section{PROCENA STANJA OBJEKTA}

\subsection{Tehnički opis konstrukcije}

Zgrada Sokolskog doma izgrađena je u periodu od 1934 do 1936. godine, prema projektu arhitekte Đorđa Tabakovića i statičkom proračunu inž. Dušana Tošića. Zvanični naziv objekta je Spomen dom Kralja Aleksandra I Ujedinitelja.

Osnova objekta je simetična, oblika izduženog pravougaonika ukupne dužine $100,14 \mathrm{~m}$ i najveće širine $34,24 \mathrm{~m}$.

Objekat se sastoji iz centralnog ulaznog dela na koji se nastavljaju dva bočna krila sa dva poprečno postavljena aneksa. Delovi su visina redom 18,5, 13,5m i 16m.

Ukupna površina objekta iznosi $2215 \mathrm{~m}^{2}$, a zapremina $31450 \mathrm{~m}^{3}$.

Parcela je ograničena sa sve četiri strane ulicama Ignjata Pavlasa, Ise Bajića, Ilije Ognjanovića i Konstantina Danila.

Konstruktivni sistem je mešovit, sadrži elemente masivnog zidanog sistema (zidovi i stubovi) i skeletnog armirano-betonskog sistema (stubovi) sa krutim međuspratnim tavanicama i horizontalnim serklažima, sa izuzetkom krovne konstrukcije iznad velike sale.

Objekat je fundiran na trakastim temeljima. Dubina fundiranja iznosi $-2,8 \mathrm{~m}$, dok deo podruma u kome je smešteno centralno grijanje je fundirano na dubini $-4,6 \mathrm{~m}$.

Tema master rada je vezana za levo krilo zgrade Sokolskog doma.

Vertikalna komunikacija smeštena u kulama zgrade ostvarena je pomoću dvokrakog armiranobetonskog stepeništa sa podestnom pločom u sredini.

Međuspratnu konstrukciju objekta čini puna armiranobetonska ploča koja prenosi opterećenje u jednom pravcu.

Tavanska ploča je puna armirano-betonska ploča na koju se u kulama oslanja drvena krovna konstrukcija na četiri vode, odnosno između njih je drveni krov na jednu vodu, preko kojih je pružen limeni pokrivač.

Krovna konstrukcija iznad velike sale sastoji se od šest trapezastih drvenih rešetki sa ispunom od dijagonala i vertikala, koje su ojačane čeličnim rešetkama i međusobno povezane spregovima u gornjem i donjem pojasu. Završni pokrivač je čelični lim. Tavanska ploča iznad velike sale je drvena međuspratna konstrukcija ispunjena peskom, a sa donje strane zatvorena lamperijom.

\subsection{Vizuelni pregled objekta}

Kako bi procenilli stanje konstrukcije objekta urađen je detaljan vizuelni pregled koji obuhvata proveru geometrije objekta i dimenzija konstruktivnih elemenata, registrovanje i klasifikaciju vidljivih oštećenja, odnosno prikupljanje što više informacija potrebnih za formiranje zaključka o stanju konstrukcije [1].

\subsubsection{Analiza oštećenja spoljašnjih površina}

Vlaga je veoma prisutna u zidovima objekta, kako atmosferska, tako i kapilarna i uzrokuje bubrenje i otpadanje maltera na svim zidovima kula.

$\mathrm{Na}$ ogradi su se pojavila oštećenja u vidu drobljenja i otpadanja komada opeke usled dejstva mraza i kristalizacije soli. Takođe, je uočeno i ispiranje malterskih malterskih spojnica između opeka.

$\mathrm{Na}$ zidovima, posebno uz tlo, vlažna sredina stvara pogodne uslove za razvoj biološke korozije.

Odvajanje, bubrenje i otpadanje dekorativnog maltera je posledica kapilarnog upijanja vode i kristalizacije soli usled nedostatka hidroizolacije ili korišćenja neadekvatnih premaza koji sprečavaju difuziju vodene pare.

Uočena su i mehanička oštećenja različitih vrsta i uzroka nastanka.

Grafiti narušavaju estetski izgled objekta.

Do pucanja kulir pločica došlo je ili usled nedovoljno zbijene podloge ili usled ispiranja nabijenog peska koji je postao neravan i doveo do pucanja krtih pločica tokom korištenja.

Pukotine u soklama od veštačkog kamena posledica su ili dugotrajnog skupljanja prilikom očvršćavanja maltera ili zamora materijala usled termičkog rada.

\subsubsection{Analiza oštećenja unutrašnjih površina}

Najizraženija oštećenja u unutrašnjosti objekta su pukotine i malter koji je počeo da se ljuska i otpada.

Mesta značajnih prslina i pukotina su zidovi i grede suterena. Uzrok nastanka je nepoznat.

Ljuskanje i otpadanje maltera nastalo je usled prisustva vlage u zidovima koja je dospela na različite načine, kao što su difuzija vodene pare, prolazak vode kroz instalacije ili prozore, nepostojanje hidorizolacije [4].

Ljuskanje završnog sloja je karakteristično za toalete i kupatila sa saunom u kojima je svakodnevno pristuna velika količina vlage.

Dotrajale i popucale teraco i keramičke pločice posledica su dugotrajnog korištenja.

Rupe u zidovima koje su služile ili za provlačenje instalacija ili za kačenje rekvizita nisu adekvatno popunjene.

\subsection{Zaključak o stanju objekta}

$\mathrm{Na}$ osnovu izvršene analize oštećenja i otkrivanja njihovih uzroka zaključuje se da je glavni problem objekta vlaga, kao i dotrajalost pojedinih delova. 
Razni su načini na koje je voda dospela u elemente objekta, kao što su kapilarno upijanje podzemne vode, difuzijom vodene pare i njenim neadekvatnim odvođenjem, nepravilno odvodnjavanje vode sa krova i procurivanje instalacionih cijevi.

Takođe, deo prozora je dotrajao, oni od čelika su korodirali i propuštaju vodu.

Kako bi otkrili uzrok nastanka pukotina potrebno je ukloniti postojeći malter i izvesti dodatna ispitivanja.

Može se zaključiti da je objekat u solidnom stanju. Skorom sanacijom uklonjeni su mnogi nedostaci. Stabilnost i nosivost objekta nisu narušene, dok trajnost $i$ funkcionalnost jesu delimično.

Prilikom sanacije najvažnije je otkloniti izazivače oštećenja, a ne samo ih sanirati, jer se u tom slučaju neće ponovo vratiti.

\section{PRORAČUN ENERGETSKE EFIKASNOSTI TRENUTNOG STANJA OBJEKTA}

Elaborat energetske efikasnosti izrađen je prema važećem Pravilniku o energetskoj efikasnosti zgrada, „Službeni glasnik RS“ br. 61/2011.

Definisano je 25 netransparentnih pozicija, od toga 16 spoljašnjih zidova, 3 ploče na tlu, 3 krovne ploče, 2 ploče iznad otvorenog prolaza i 1 vrata. Transparentnih pozicija ima ukupno 13, od kojih je 10 prozora i 3 vrata. Odrađen je proračun građevinske fizike za svaku od pozicija (prolaz temperature, difuzija vodene pare, proračun letnje stabilnosti).

U Tabeli 1 su date vrednosti koeficijenta prolaza toplote $\mathrm{U}$, po pozicijama, i podatak o ispunjavaju uslova o najvećem dozvoljenom koeficijentu U.

Potom izačunati su transmisioni gubici kroz transparentne i netransparentne površine, ventilacioni i linijski gubici, kao i dobici od sunčevog zračenja i unutrašnjih izvora. Zaključeno je da su najveći gubici energije kroz netransparentne elemente $(101.86 \mathrm{~kW})$ i ventilacioni gubici $(109.71 \mathrm{~kW})$ (Slika 2).

Proračunom je dobijena ukupna potrebna energija za grejanje za slučaj sistema koji radi bez prekida, kao i po mesecima. Na osnovu sprovedenog proračuna, zgrada se svrstava u energetski razred $\mathrm{G}$.

Ukupni gubici toplote

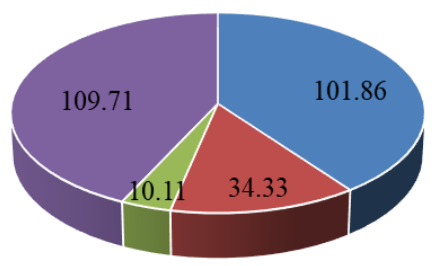

- Transmisioni gubici kroz netransparentne površine

- Transmisioni gubici kroz transparentne površine

- Linijski gubici

- Ventilacioni gubici

Slika 2. Energetski gubici na postojećem objektu
Tabela 1. Vrednosti koeficijenta prolaza toplote Ui

\begin{tabular}{|c|c|c|c|c|}
\hline Element & Pozicija & $\mathrm{U}\left(\mathrm{W} / \mathrm{m}^{2} \mathrm{~K}\right)$ & $\mathrm{U}_{\max }\left(\mathrm{W} / \mathrm{m}^{2} \mathrm{~K}\right)$ & Uslov zadovoljen \\
\hline \multirow{21}{*}{ Spoljašnji zidovi } & SZ1a & 0.931 & 0.4 & $\mathrm{Ne}$ \\
\hline & SZ1b & 0.765 & 0.4 & $\mathrm{Ne}$ \\
\hline & SZ2a & 0.76 & 0.4 & $\mathrm{Ne}$ \\
\hline & SZ2b & 0.575 & 0.4 & $\mathrm{Ne}$ \\
\hline & SZ3a & 0.943 & 0.4 & $\mathrm{Ne}$ \\
\hline & SZ3b & 0.888 & 0.4 & $\mathrm{Ne}$ \\
\hline & $\mathrm{SZ3c}$ & 1.009 & 0.4 & $\mathrm{Ne}$ \\
\hline & SZ4 & 1.095 & 0.4 & $\mathrm{Ne}$ \\
\hline & SZ5 & 1.081 & 0.4 & $\mathrm{Ne}$ \\
\hline & SZ6 & 0.812 & 0.4 & $\mathrm{Ne}$ \\
\hline & SZ7 & 0.954 & 0.4 & $\mathrm{Ne}$ \\
\hline & SZ8 & 0.772 & 0.4 & $\mathrm{Ne}$ \\
\hline & SZ9 & 1.703 & 0.4 & $\mathrm{Ne}$ \\
\hline & SZ10 & 0.411 & 0.4 & $\mathrm{Ne}$ \\
\hline & SZ11a & 1.614 & 0.4 & $\mathrm{Ne}$ \\
\hline & SZ11b & 1.784 & 0.4 & $\mathrm{Ne}$ \\
\hline & $\mathrm{SZ12}$ & 0.819 & 0.4 & $\mathrm{Ne}$ \\
\hline & SZ13 & 0.943 & 0.4 & $\mathrm{Ne}$ \\
\hline & SZ14 & 1.866 & 0.4 & $\mathrm{Ne}$ \\
\hline & SZ15 & 0.565 & 0.4 & $\mathrm{Ne}$ \\
\hline & SZ16 & 0.645 & 0.4 & $\mathrm{Ne}$ \\
\hline \multirow{3}{*}{ Ploča na tlu } & PT1 & 1.69 & 0.4 & $\mathrm{Ne}$ \\
\hline & $\mathrm{PT} 2$ & 1.698 & 0.4 & $\mathrm{Ne}$ \\
\hline & PT3 & 1.63 & 0.4 & $\mathrm{Ne}$ \\
\hline \multirow{2}{*}{ Podna ploča } & PP1 & 0.256 & 0.3 & $\mathrm{Da}$ \\
\hline & PP2 & 0.256 & 0.3 & $\mathrm{Da}$ \\
\hline \multirow{3}{*}{ Krovna ploča } & KP1 & 0.29 & 0.4 & $\mathrm{Da}$ \\
\hline & $\mathrm{KP} 2$ & 0.383 & 0.4 & $\mathrm{Da}$ \\
\hline & KP3 & 0.2 & 0.2 & $\mathrm{Da}$ \\
\hline \multirow{19}{*}{ Prozori } & PR1a & 1.19 & 1.5 & $\mathrm{Da}$ \\
\hline & PR1b & 1.17 & 1.5 & $\mathrm{Da}$ \\
\hline & PR2 & 1.12 & 1.5 & $\mathrm{Da}$ \\
\hline & PR3 & 0.94 & 1.5 & $\mathrm{Da}$ \\
\hline & PR4a & 1.34 & 1.5 & $\mathrm{Da}$ \\
\hline & PR4b & 1.24 & 1.5 & $\mathrm{Da}$ \\
\hline & PR5a & 1.13 & 1.5 & $\mathrm{Da}$ \\
\hline & PR5b & 1.09 & 1.5 & $\mathrm{Da}$ \\
\hline & PR6a & 1.13 & 1.5 & $\mathrm{Da}$ \\
\hline & PR6b & 1.11 & 1.5 & $\mathrm{Da}$ \\
\hline & PR7a & 1.08 & 1.5 & $\mathrm{Da}$ \\
\hline & PR7b & 1.06 & 1.5 & $\mathrm{Da}$ \\
\hline & PR8a & 0.78 & 1.5 & $\mathrm{Da}$ \\
\hline & PR8b & 0.86 & 1.5 & $\mathrm{Da}$ \\
\hline & PR8c & 0.77 & 1.5 & $\mathrm{Da}$ \\
\hline & PR9a & 1.15 & 1.5 & $\mathrm{Da}$ \\
\hline & PR9b & 1.14 & 1.5 & $\mathrm{Da}$ \\
\hline & PR10a & 1.15 & 1.5 & $\mathrm{Da}$ \\
\hline & PR10b & 1.14 & 1.5 & $\mathrm{Da}$ \\
\hline \multirow{7}{*}{ Vrata } & VR1a & 1.31 & 1.5 & $\mathrm{Da}$ \\
\hline & VR1b & 1.31 & 1.5 & $\mathrm{Da}$ \\
\hline & VR2a & 1.33 & 1.5 & $\mathrm{Da}$ \\
\hline & VR2b & 1.39 & 1.5 & $\mathrm{Da}$ \\
\hline & VR3a & 1.2 & 1.5 & $\mathrm{Da}$ \\
\hline & VR3b & 1.2 & 1.5 & $\mathrm{Da}$ \\
\hline & VR4 & 1.38 & 1.5 & $\mathrm{Da}$ \\
\hline
\end{tabular}

\section{MERE ENERGETSKE SANACIJE I PRORAČUN ENERGETSKE EFIKASNOSTI SANIRANOG STANJA OBJEKTA}

Sanacija objekta se sprovodi prema najvećim gubicima.

U slučaju objekta Sokolskog doma energetska sanacija objekta obuhvata međuspratne ploče (PP1 i PP2) i sve krovne ploče (KP1, KP2 i KP3), kao i zamenu svih prozora i vrata na objektu.

Energetska sanacija određenih netransparentnih površina podrazumeva izolaciju toplotno-izolacionim materijalom, i to su YTONG multipor ploče debljine [4] dobijene iz uslova zadovoljenja vrednosti Umax, kao i meka staklena 
vuna i kamena vuna kod krovne ploče (KP1), a drvena lamperija treba da se zameni gipsanim pločama.

Svi transparantni elementi se menjaju. Brinući o stabilnosti prozora $\mathrm{u}$ velikoj $\mathrm{u}$ velikoj sali, izabran je aluminijumski okvir i trostruko, niskoemisiono, 4-8-4-8-4 mm staklo sa helijumskim punjenjem (Xe). Tip stakla korišćen za sve ostale prozore i vrata je dvostruko, niskoemisiono, 4-12-4 mm (Xe) staklo, dok su svi okviri aluminijumski, poboljšani [1]. Kod vrata korišćen je i aluminijumski panel debljine $25 \mathrm{~mm}$ [12].

Ponovljen je proračun energetske efikasnosti za ove novodefinisane sklopove. Nakon proračuna građevinske fizike i proračuna gubitaka, uviđa se da su predmetne vrednosti znatno smanjene (Slika 3).

Ukupni gubici toplote

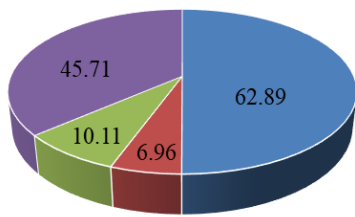

- Transmisioni gubici kroz netransparentne površine

- Transmisioni gubici kroz transparentne površine

- Linijski gubici

- Ventilacioni gubici

\section{Slika 3. Energetski gubici na saniranom objektu}

Nakon proračuna dobitaka i potrebne energije za grejanje ostvaren je energetski razred saniranog objekta - "D".

\section{ZAKLJUČAK}

U praktičnom delu rada izvršena je procena stanja objekta Sokolskog doma, prilikom koje je zaključeno da je objekat u solidnom stanju. Iako su skorom sanacijom uklonjeni mnogi, nedostaci još uvek postoje. Stabilnost i nosivost objekta nisu narušene, dok trajnost i funkcionalnost jesu delimično.

Urađen je proračun energetske efikasnosti, na osnovu kog je objekat katergorizovan u energetski razred G, slika 4 .

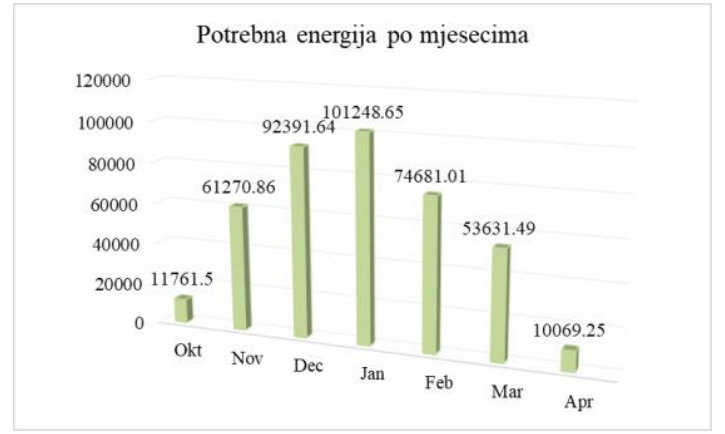

Slika 4. Potrebna energija za zagrevanje postojećeg objekta

U cilju povećanja trajnosti objekta, ali i smanjenja količine energije potrebne za zagrejavanje objekta, poboljšane su karakteristike određenih elemenata. Na mestima gde je bila potrebna izolacija postavljene su Ytong Multipor ploče, kao i staklena i kamena vuna, dok su na prozorima i vratima zamenjena stakla i okviri, upotrebljavajući ona sa mnogo boljim izolacionim karakteristikama.
Ponovljenim proračunom energetske efikasnosti sanirani objekat pripao je energetskom razredu D, čime se sanacija smatra uspešno izvršenom (slika 5).

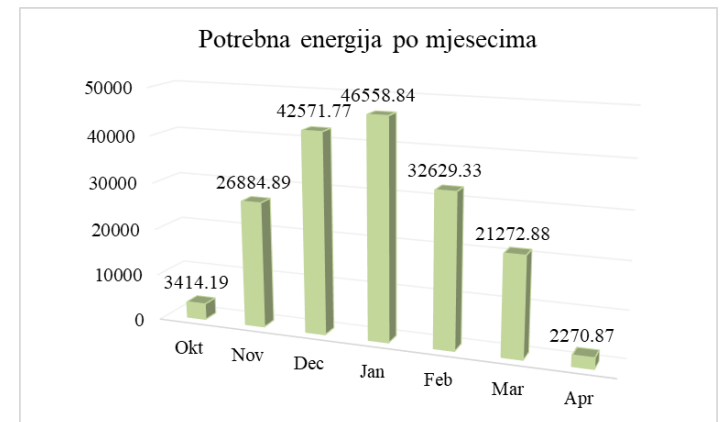

Slika 4. Potrebna energija za zagrevanje energetski saniranog objekta

\section{LITERATURA}

[1] Inženjerska komora Srbije: Pravilnik o energetskoj efikasnosti zgrada, "Sl. glasnik RS", br.

61/2011, Beograd

[2] Inženjerska komora Srbije: Predavanja za obuku o energetskoj efikasnosti zgrada, Beograd,

2012.

[3] Malešev M., Radonjanin V.: Trajnost i procena stanja betonskih konstrukcija, Skripta sa predavanja, Fakultet tehničkih nauka, Novi Sad [4] Malešev M., Radonjanin V.: Oštećenja i sanacija zidanih, čeličnih i drvenih konstrukcija, Skripta sa predavanja, Fakultet tehničkih nauka, Novi Sad [5] Protić-Gava B., Paunović J., Kovačev M.: 110 godina novosadskog Sokolskog društva i 164 godine gimnastike u Novom Sadu

[6] Fotomonografija novosadskog Sokolskog društva [7] https://www.gimnastika-

ns.rs/index.php?option=com_content $\&$ view $=$ article $\&$ id $=9$

$2 \&$ Itemid $=155$

[8] https://www.kanal9tv.com/sokolski-dom-cuvatradiciju/

[9] https://www.youtube.com/watch?v=3n4gs-JRUZI

[10] http://pozoristemladih.co.rs/o-nama/istorijat

[11]https://www.researchgate.net/publication/283029803

_Uloga_i_znacaj_Sokolskog_doma_u_razvoju_Novog_S ada_The_Role_and_Importance_of_Sokolski_dom_in_D evelopment_of_Novi_Sad

[12] https://lyctum.com/assets/files/pdf/tehnicke-

karakteristike-isoleader-panisol-mdf-al.pdf

[13] https://www.ytong.rs/sta_je_ytong_multipor_1798.php

\section{Kratka biografija:}

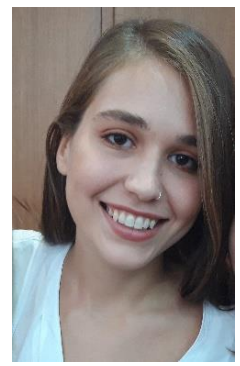

Anja Blagojević rođena je u Prijedoru 1995. godine. Master rad na Fakultetu tehničkih nauka iz oblasti Građevinarstvo - Konstrukcije, procena stanja i sanacija betonskih konstrukcija odbranila je 2021 . godine.

Kontakt: anj.blagojevic@gmail.com 